\title{
Utilization of Altmetrics as a Measure of Trust of Archival Data
}

\author{
Mohammad M. AlHamad \\ Abu Dhabi Polytechnic, Abu Dhabi, UAE
}

\begin{abstract}
Altmetrics is a new method that is currently used to capture the impact of published scholarly works based on data visibility on the web as a supplement to traditional bibliometric methods. On the other hand, archives contain venerable data that can be extremely helpful to the scholars and public. However, there is no measurement tool that can measure the value and the impact of archival data. Therefore, the aim of this paper is to explore the potentials of embracing altmetrics as a trusted measure of archival data, especially with the lack of studies on altmetrics adoption by archives and cultural heritage organizations.
\end{abstract}

Keywords: archival data, archives, altmetrics, bibliometric methods

\section{Introduction}

It is important to understand the value of unstructured metadata in supporting the users' engagement with records and archives. However, there are limited studies that cover this area. This limitation exists; it is observed that, because of financial constraints in recruiting experts, a lack of skills among archivists as well as the time required to conduct a user-based evaluation (Kelly, 2017; Duff, Dryden, Limkilde, Cherry, \& Bogomazova, 2008). In addition, the volume of records keeps expanding exponentially and, therefore, creates a need to have a reliable method to measure the value, visibility, reliability, and the impact of these records (Papakostidis \& Giannoudis, 2018). At the same time, communication methods continue to evolve with and about archives in the era of social networking platforms (Kelly, 2017). A new method called altmetrics (alternative metrics) which is currently used to capture the impact of published scholarly works as a supplement to traditional bibliometric methods may be used on archives to find the impact of the online holdings, including the unpublished electronic collections, digital repositories, and government information (Thelwall, Haustein, Larivière, \& Sugimoto, 2013; Kelly, 2017; Das, 2015).

\section{Archival Data}

Archival data are defined as information that have been previously aggregated by others and can be utilized in systematic studies (Jones, 2010). There are five major categories of archival data that have been classified in previous literature (Jones, 2010; Singleton \& Straits, 2005)—public documents and official records; private documents; mass media; physical, nonverbal materials; and social science data archives. The use of archival data research process involves one or more of these purposes: "general research procedures (e.g., procuring data, data documentation, data sharing), research design (e.g., cross-sectional, short-term longitudinal, long-term longitudinal designs), measures (e.g., types of measures used, missing measures), and samples (e.g., sample size, sample type)" (Jones, 2010, p. 1011). 


\begin{abstract}
Altmetrics
Altmetrics is a relatively new discipline of analyzing scholarship based on data visibility on the web (including social media, mainstream media mentions, peer reviews, and citations to research in policy documents) (Priem, Taraborelli, Groth, \& Neylon, 2010). Altmetrics measure a broad aspect of research visibility and impact in comparison to bibliometric methods, and provide a supplement to the traditional impact factor methodology based on citation filters (Fenner, 2014). For instance:

(1) Citation, h-index, and journal impact take relatively long time to be measured waiting for the cycle of publication to be completed and for studies to be cited by others.

(2) Bibliometric methods overlook new forms of scholarly content, such as scripts, videos, datasets, conference, news, presentation slides, and research blogs.

(3) Altmetrics can capture the impact of research outside of academic publishing, potentially resulting in the discovery of unidentified readers, and identify value further than the traditional scholarly consumption groups.

(4) The current impact factor methodologies embrace a "quantity over quality" argument. However, altmetrics analyze social media conversations about publications and analyze the reason for mentioning or citing a work.

(5) The journal impact factor explores the impact of entire journals; altmetrics instead explore the impact of each individual publication.

Stacy Konkiel and Dave Scherer (2013) indicated three values for using altmetrics to institutional repositories. First, altmetrics can be used by repository administrators in persuading the potential depositors that there is added value in providing open access to their content. In other words, increasing altmetrics scores might have an impact on increasing the deposit rates. Second, collecting figures beyond general usage statistics can inform university administrators the value of the institutional repositories as a platform for hosting open access content. In addition, understanding the impact of repository content on the community can be used to build a case for community engagement. Third, altmetrics can complement traditional usage statistics to support collection development plans, and can be used for resource allocation and marketing purposes.

Altmetrics are categorized in the following ways (Cave, 2012): usage (e.g., HTML views, PDF/XML downloads, and book holdings), captures (e.g., bookmarks, favorites, readers, and groups), mentions (e.g., blog posts, news stories, Wikipedia articles, comments, and reviews), social media (e.g., user activity from Twitter, Google+, and Facebook), and citations (e.g., CrossRef, PubMed Central, Web of Science, Scopus, and Microsoft Academic Search).
\end{abstract}

\title{
Archives and Altmetrics
}

The lack of studies on altmetrics adoption by archives and cultural heritage organizations does not say that these institutions are not embracing social media. Indeed, there are many studies conducted on the use of social media by archives and cultural heritage organizations, however, these studies focus on the use of social media to increase the awareness of archives, instead of studying their impact on archival holdings (Kelly, 2017). For example, there is scholarship available to guide repositories in planning and evaluating their social media activities. These guidelines indicate the need for engaging and encouraging conversation about archival holdings by utilizing web technologies. In a study on the use of social media by repositories, Robert Schier 
(2011) stated that many repositories adopt social media as a tool to promote their collection instead of establishing a trusted relationship with users. Another study showed that special collection departments in research libraries have succeeded in using social media for promoting purposes. However, they were less successful in developing relationships via social media and engaging with external users (Griffin \& Taylor, 2013).

The value of capturing users' feedback on archives, and the difficulty to do so, were highlighted in previous studies. Martha O'Hara Conway and Merrilee Proffitt (2012) mentioned that assessing archival collections is essential for helping institutions become more user-centered. Lisa R. Carter (2012) argued that knowing the collections and how they are used can help with writing grants, informing new accessions, and in evaluating the workflow and instruction. They also stated that collecting user-driven data that measure how scholars interact with the tools available is critical.

A study published in 2008 about archivists' views of user-based evaluation found that archivists valued user feedback, but the evaluations lacked standardized measures (Duff et al., 2008). For example, the study indicated that users based value on the "success of the user's most recent search or visit" (Duff et al., 2008). In another study, user feedback about their use of digital collections was found to be vital for collecting institutions to prosperously demonstrate the significance of their collections (Marsh, Punzalan, Leopold, Butler, \& Petrozzi, 2015). However, archives assessment demonstrates a shortage of "reliable measures of institutional impact or nuanced portraits of audience engagement", as reported in a yearlong interdisciplinary research on assessing and indicating the value and impact of digitized ethnographic collections (Marsh et al., 2015). Furthermore, the lack of methods for using data-driven decision-making in institutions impacts the change and definition of metrics which allow for cross-institutional comparison (Chapman \& Yakel, 2012).

There are many potential benefits for using altmetrics for archives (Kelly, 2017). Altmetrics can facilitate new methods of tracking collections, where archives can find discussion of their collections in virtual spaces. This may provide archives an opportunity to show the effect and influence of their holding in both academic and non-academic environments. Likewise, since altmetrics capture data beyond scholarly works, altmetrics may help archivists better understand the diversity and representation of how collections are being used. Moreover, archives can enhance other services by adopting altmetrics to influence decisions about digitization, accessions, and processing priorities, as discussion of users' needs in these areas may be occurring online.

\section{Conclusions}

Altmetrics is an area under development, with a big potential to be applied on non-scholarly work, such as the archival data. However, since there are many altmetrics providers in the market, it is necessary to have a unified algorithm to measure the altmetrics score of the archival data.

\section{References}

Carter, L. R. (2012). Articulating value: Building a culture of assessment in special collections. RBM: A Journal of Rare Books, Manuscripts, and Cultural Heritage, 13(2), 89-99.

Cave, R. (2012). Overview of the altmetrics landscape. In Proceedings of the Charleston Library Conference (pp. 349-356). West Lafayette: Purdue University Press.

Chapman, J., \& Yakel, E. (2012). Data-driven management and interoperable metrics for special collections and archives user services. RBM: A Journal of Rare Books, Manuscripts, and Cultural Heritage, 13(2), 129-151.

Conway, M. O. H., \& Proffitt, M. (2012). The practice, power, and promise of archival collections assessment. RBM: A Journal of Rare Books, Manuscripts, and Cultural Heritage, 13(2), 100-112. 
Creswell, J. W. (2013). Research design: Qualitative, quantitative, and mixed methods approaches. London: SAGE.

Das, T. (2015). Measuring scholarly use of government information: An altmetrics analysis of federal statistics. Government Information Quarterly, 32(3), 246-252.

Duff, W., Dryden, J., Limkilde, C., Cherry, J., \& Bogomazova, E. (2008). Archivists' views of user-based evaluation: Benefits, barriers, and requirements. The American Archivist, 71(1), 144-166.

Fenner, M. (2014). Altmetrics and other novel measures for scientific impact. In S. Bartling and S. Friesike (Eds.), Opening science (pp. 179-189). Springer International Publishing.

Griffin, M., \& Taylor, T. I. (2013). Of fans, friends, and followers: Methods for assessing social media outreach in special collections repositories. Journal of Web Librarianship, 7(3), 255-271.

Hicks, D., Wouters, P., Waltman, L., De Rijcke, S., \& Rafols, I. (2015). The Leiden Manifesto for research metrics. Nature, 520(7548), 429-431.

Jones, C. (2010). Archival data: Advantages and disadvantages for research in psychology. Social and Personality Psychology Compass, 4(11), 1008-1017.

Kelly, E. J. (2017). Altmetrics and archives. Journal of Contemporary Archival Studies, 4(1), 1-22.

Konkiel, S., \& Scherer, D. (2013). New opportunities for repositories in the age of altmetrics. Bulletin of the Association for Information Science and Technology, 39(4), 22-26.

Marsh, D. E., Punzalan, R. L., Leopold, R., Butler, B., \& Petrozzi, M. (2016). Stories of impact: The role of narrative in understanding the value and impact of digital collections. Archival Science, 16(4), 327-372.

Papakostidis, C., \& Giannoudis, P. V. (2018). Impact factor and altmetrics: What is the future? In C. Mauffrey and M. M. Scarlat (Eds.), Medical writing and research methodology for the orthopaedic surgeon (pp. 71-79). Cham: Springer.

Priem, J., Taraborelli, D., Groth, P., \& Neylon, C. (2010). Altmetrics: A manifesto. Retrieved from http://altmetrics.org/manifesto/

Schrier, R. A. (2011). Digital librarianship \& social media: The digital library as conversation facilitator. D-Lib Magazine, 17(7), 2. Retrieved from http://www.dlib.org/dlib/july11/schrier/07schrier.html

Singleton, R. A. Jr., \& Straits, B. C. (2005). Approaches to Social research. New York: Oxford University Press.

Thelwall, M., Haustein, S., Larivière, V., \& Sugimoto, C. R. (2013). Do altmetrics work? Twitter and ten other social web services. PloS One, 8(5), e64841.

Turiano, N. A. (2014). Archival data analysis introduction. The International Journal of Aging and Human Development, 79(4), 323-325. 